Eur. J. Clin. Chem. Clin. Biochem.

Vol. 32, 1994, pp. 383-389

(c) 1994 Walter de Gruyter \& Co.

Berlin · New York

\title{
An Immunoinhibition Assay for Determination of Creatine Kinase Isoforms in Serum
}

\author{
By M. Panteghini, R. Bonora and Franca Pagani \\ $I^{\circ}$ Laboratorio Analisi Chimico-Cliniche, Settore di Chimica Clinica ed Enzimologia, Spedali Civili, Brescia, Italy
}

(Received October 28, 1993/February 10, 1994)

Summary: We report a preliminary evaluation of an immunoinhibition assay for creatine kinase isoform quantification. The procedure employs the monoclonal antibody CKM-G01, which inhibits the native $\mathrm{M}$ subunit of creatine kinase. The antibody does not inhibit the $\mathrm{M}$ subunit modified by removal of lysine by plasma carboxypeptidase $\mathrm{N}$. Residual activity after treatment with the antibody is therefore due to serum delysinated isoforms. The ratio inhibited/residual activity correlated directly with the ratio tissue/serum isoforms. Analysis of the total imprecision of isoform ratio measurement gave a coefficient of variation between 5.9 and $21.1 \%$. Reference intervals for the ratio were $0.14-0.79$ in females and $0.19-0.95$ in men $(p=0.0046)$. Analytical and clinical comparison with alternative isoform procedures gave good results, showing that this assay can be used as alternative to the widely accepted electrophoretic method for measurement of the creatine kinase isoform ratio.

\section{Introduction}

High resolution separation techniques have shown the presence of multiple forms of creatine kinase (ATP: creatine $\mathrm{N}$-phosphotransferase, EC 2.7.3.2) isoenżymes in human serum (for review see 1.c. (1)). It has been well documented that there are at least three creatine kinase MM isoforms (subforms derived from the same isoenzyme that exhibit the same specific catalytic activity and slightly different isoelectric points), denoted as $\mathrm{MM} 1, \mathrm{MM} 2$, and $\mathrm{MM} 3$, and two creatine kinase $\mathrm{MB}$ isoforms, denoted as MB1 and MB2 (2). Only MM3 and MB2 (the gene-encoded forms) are present in extracts of muscle tissue, whereas MM2, MM1, and MB1 represent the additional forms produced post-translationally by hydrolytic removal of the carboxy-terminal lysine residue on the native $M$ subunit by plasma carboxypeptidase $\mathrm{N}(3)$.

The clinical utility of creatine kinase isoform determination has been actively investigated $(1,2,4)$. Determination of the isoforms in the serum of patients with acute myocardial infarction provides an early detection of acute enzyme release from necrotic myocardium (5, 6) and distinguishes between reperfused and non-reper- fused patients after thrombolytic therapy (7-9). In particular, the ratio of the tissue isoforms (i.e., the gene products) to the serum isoforms is diagnostically more sensitive than the concentrations of individual isoforms $(1,2)$. However, due to technical limitations of current analytical methods, determination of the isoform ratio appears to be too cumbersome and slow for therapeutic and management decision making (10). Indeed, a simple, rapid, and automated method for measuring creatine kinase isoforms suitable for routine analysis, is still lacking (11). Significant improvement would be expected with immunoassay methods. Two diagnostic reagents, using isoform-specific monoclonal antibodies, were recently introduced $(12,13)$. However, one procedure determines only the MM1 isoform, whereas the examination of the performance of the antibodies used in the latter demonstrated significant cross-reaction with different isoforms (14).

In 1990, Suzuki et al, (15) described a monoclonal antibody (CKM-G01) that inhibited $>99 \%$ of the activity of human creatine kinase purified from muscle but approximately $55 \%$ of creatine kinase activity in serum. Chromatofocusing analysis revealed that CKM-G01 
specifically inhibited only the original creatine kinase $M$-subunit and not the subunit modified by removal of carboxy-terminal lysine by serum carboxypeptidase (15). Using CKM-G01, an immunoinhibition method was devised by Iatron Laboratories (Tokyo, Japan). Since the antibody inhibited MM3 completely, approximately $50 \%$ of MM2 and MB2, and does not inhibit MM1 and MB1 activities, it was possible to calculate an "inhibition index" expressing the ratio of the tissue isoforms with lysine on the $\mathrm{M}$ monomer, to the serum isoforms with no lysine at carboxy terminus of the $M$ monomer. Notwithstanding two preliminary studies published as "Abstracts" by the Iatron research group (16, 17), we report here the first comprehensive evaluation of this automated assay since its commercialization, with a wider documentation of its analytical performance and a preliminary study on its clinical value for the differentiation of acute myocardial infarction patients with successful or non-successful reperfusion after thrombolytic therapy.

\section{Materials and Methods}

\section{Analytical procedures}

Total creatine kinase activity was determined by a coupled reaction of glucokinase and glucose-6-phosphate dehydrogenase (18), using a diagnostic kit (Iatro-CK; Iatron Laboratories Inc.). Two reagents were used: reagent A was $75 \mathrm{mmol} / 1$ imidazole acetate buffer $(\mathrm{pH}$ 6.7) containing, per litre, $1.8 \mathrm{mmol}$ adenosine 5'-diphosphate, 2.5 mmol nicotinamide adenine dinucleotide phosphate, $25 \mathrm{mmol}$ glucose, $25 \mathrm{mmol} \mathrm{N}$-acetylcysteine, $2.4 \mathrm{mmol}$ ethylenediaminetetraacetic acid, $12 \mu \mathrm{mol}$ diadenosine pentaphosphate, $5 \mathrm{mmol}$ adenosine 5'-monophosphate, $4000 \mathrm{U}$ glucokinase and $1300 \mathrm{U}$ glucose-6phosphate dehydrogenase. Reagent B was $25 \mathrm{mmol} / \mathrm{l}$ Tris buffer (pH 7.5) containing, per litre, $130 \mathrm{mmol}$ creatine phosphate and 50 mmol magnesium acetate. We applied this method to the Cobas Bio analyser (Hoffman-La Roche, Basle, Switzerland). After the sample $(4 \mu \mathrm{l}$, diluent volume $30 \mu \mathrm{l})$ had been incubated with 130 $\mu l$ of reagent $A$ for 3 minutes at $37^{\circ} \mathrm{C}$, the reaction was started by addition of $20 \mu \mathrm{l}$ of reagent $\mathrm{B}$. The increase in absorbance of reduced nicotinamide adenine dinucleotide phosphate at $340 \mathrm{~nm}$ was monitored for the sample vs the reagent blank for 150 seconds, after a 60 -second lag phase. Creatine kinase activity was expressed as $U / 1$ (micromoles of substrate converted per minute per litre). For the comparison studies, total creatine kinase activity was measured at $37^{\circ} \mathrm{C}$ by the method recommended by the International Federation of Clinical Chemistry, with reagents from Boehringer, Mannheim, Germany.

The immunoinhibition assay was done by the method for creatine kinase described above, except that $1 \mathrm{mg} / 1$ of the monoclonal antibody CKM-G01, obtained from latron, was added to reagent $A$. A creatine kinase isoform ratio was calculated from total and residual (not-inhibited) activities as follows: total creatine kinase - residual creatine kinase/residual creatine kinase.

Two creatine kinase isoform procedures were utilized for the comparison studies. Complete creatine kinase $\mathrm{MM}$ and $\mathrm{MB}$ isoform patterns were separated by electrophoresis ( $1400 \mathrm{~V}$ for 16 minutes) on agarose gel with the automated Rapid Electrophoresis Analyser/ Electronic Data Center - REP/EDC ${ }^{\mathrm{TM}}$ system (Helena Laboratories, Beaumont, TX 77704, USA). After electrophoresis, the gel was treated with the creatine kinase substrate reagent (REP CK Isoforms Reagent, Helena Laboratories) at $45^{\circ} \mathrm{C}$, then dried for 5 minutes at $54^{\circ} \mathrm{C}$. Isoforms were detected by fluorescence densito- metry. Specimens with total creatine kinase activity exceeding $1000 \mathrm{U} / \mathrm{l}$ were diluted before analysis. Additionally, the creatine kinase MM1 isoform, i.e. the serum-specific isoform, was determined by an immunochemical procedure as previously described (12). Since the MM1 isoform is the principal component of noninhibited activity in the evaluated assay (see above), the results of the latter method were directly compared with the remaining creatine kinase activity after inhibition with CKM-G01 antibody.

Creatine kinase $\mathrm{MB}$ mass concentrations were determined with the Magic Lite CK-MB assay (Ciba Corning Diagnostics Corp., E. Walpole, MA 02032, USA), which uses a double-antibody chemiluminescent procedure. Technical details, imprecision, and reference range for healthy individuals, $0-6 \mu \mathrm{g} / \mathrm{l}$, have been published previously (19). Myoglobin was determined with the Behringwerke immunonephelometric reagents (NA Latex Myoglobin Test, Behringwerke, Marburg, Germañy) consisting of shell and core particles coated with anti-myoglobin antibodies and adapted to the selective multiprotein Behring Nephelometer Analyser (20). The previously established upper reference limit was $45 \mu \mathrm{g} / \mathrm{l}(20)$.

The purified human creatine kinase isoforms, employed for specificity and recovery studies, were obtained from Calbiochem Corp. (La Jolla, CA 92037, USA) (MM3 isoform) and from Aalto Scientific (Vista, CA 92083, USA) (MM1 isoform). The composition of these commercially available materials was assayed by isoform electrophoresis (see above) and the homogeneity of each preparation was confirmed.

\section{Blood samples}

We studied ten patients (eight men and two women, aged 41 to 70 years) who were admitted because of acute myocardial infarction to the Department of Anaesthesia and Reanimation of our hospital, and had undergone intravenous thrombolytic therapy 177 minutes (average; range 90-240) after the onset of chest pain. The reestablishment of anterograde flow in the occluded coronary artery was assessed non-invasively by clinical, electrocardiographic, and biochemical criteria (e.g. persistence of chest pain and of electrocardiographic changes, absence of reperfusion arrhythmias, analysis of creatine kinase $\mathrm{MB}$ and myoglobin release rates) (21-23). On the basis of these criteria, five patients were successfully completely reperfused and five patients not. Peripheral venous blood samples were obtained at the time of thrombolytic therapy and approximately 2, 4 and 6 hours thereafter. Sampling time was related to the time of thrombolysis. Samples for isoform analysis were treated with ethylenediaminetetraacetic acid to give a final concentration of $5 \mathrm{mmol} / \mathrm{l}$, then stored at $-20^{\circ} \mathrm{C}$ (1). Serum samples were assayed immediately for total creatine kinase, creatine kinase $\mathrm{MB}$, and myoglobin; isoform assays were performed within 24 hours after collection, without delay after thawing the samples.

In addition, 128 non-hospitalized apparently healthy subjects ( 80 women and 48 men, whose ages ranged from 20 to. 70 years), with normal results for serum biochemical and baematological tests and without clinical evidence of cardiac and muscle diseases, were studied to establish the reference interval for creatine kinase isoforms in serum by the evaluated method.

\section{Results}

\section{Specificity of the immunological reaction}

The specificity of the inhibition was studied by using highly purified preparations of human MM3 and MM1 
Tab. 1 Recovery of creatine kinase after incubation of pure $\mathrm{MM} 3$ and MM1 isoform with monoclonal antibody CKM-G01 $(n=3)$.

\begin{tabular}{|c|c|c|c|c|c|}
\hline & \multicolumn{2}{|c|}{ MM3 isoform } & \multicolumn{3}{|c|}{ MM1 isoform } \\
\hline & Mean & SD & Mean & & SD \\
\hline $\begin{array}{l}\text { Total creatine } \\
\text { kinase (Uil) }\end{array}$ & 547 & 8.5 & 353 & & 6.0 \\
\hline $\begin{array}{l}\text { After inhibition } \\
(\mathrm{U} / \mathrm{l})\end{array}$ & 1.7 & 0.5 & 362 & & 6.4 \\
\hline Recovery (\%) & \multicolumn{2}{|c|}{0.3} & \multicolumn{3}{|c|}{102.5} \\
\hline $\begin{array}{l}\text { Total creatine } \\
\text { kinase }(U / l)\end{array}$ & 1156 & 16.4 & 702 & & 6.8 \\
\hline $\begin{array}{l}\text { After inhibition } \\
\text { (U/l) }\end{array}$ & 4.4 & 2.8 & 706 & & 13.3 \\
\hline Recovery (\%) & \multicolumn{2}{|c|}{0.4} & \multicolumn{3}{|c|}{100.6} \\
\hline $\begin{array}{l}\text { Total creatine } \\
\text { kinase (U/l) }\end{array}$ & 1568 & 12.6 & 1050 & & 8.7 \\
\hline $\begin{array}{l}\text { After inhibition } \\
\text { (U/I) }\end{array}$ & 8.6 & 1.3 & 1072 & & 8.5 \\
\hline Recovery (\%) & \multicolumn{2}{|c|}{0.5} & \multicolumn{3}{|c|}{101.7} \\
\hline $\begin{array}{l}\text { Total creatine } \\
\text { kinase (U/l) }\end{array}$ & 2887 & 16.5 & 1406 & & 10.6 \\
\hline $\begin{array}{l}\text { After inhibition } \\
(U / J)\end{array}$ & 24.6 & 2.3 & 1430 & & 10.0 \\
\hline Recovery (\%) & \multicolumn{2}{|c|}{0.9} & \multicolumn{3}{|c|}{102.1} \\
\hline
\end{tabular}

isoforms. As presented in table 1, we found practically no inhibition of the antibody with MM1 isoform, whereas CKM-G01 inhibited more than $99 \%$ of purified MM3 isoform.

Investigation of the effect of incubation time on the inactivation of the MM3 isoform showed that the inhibition was complete within 3 minutes at $37^{\circ} \mathrm{C}$ (data not shown).

\section{Reagent stability}

The working, ready to use solutions were stable for 20 days when refrigerated.

\section{Linearity}

Under the conditions described, the assay was linear for total and residual creatine kinase activity in serum up to $1500 \mathrm{U} / \mathrm{l}$. We serially diluted a creatine kinase-rich specimen with heat-inactivated serum. Five separated dilutions were assayed, and each dilution was run three times. The standard curves showed no significant curvature, when tested for linearity as suggested by Burnett (24) (for total creatine kinase activity: quadratic regression, $y=-0.46+404.54 x-9.12 x^{2}$, and for residual creatine kinase activity: quadratic regression, $y=-4.42+201.18 x-23.03 x^{2}$, where the coef- ficients of $\mathrm{x}^{2}$ did not differ significantly from zero $(p=0.206$ and $p=0.052$, respectively)).

\section{Precision}

Results of precision studies are shown in table 2. These studies included estimates of "within-run" and "total" imprecisions, each determined at normal, above-normal, and high creatine kinase isoform ratios, using appropriate samples from three patients, selected without conscious bias from a hospital population. The method of estimating imprecision was the analysis of variance experiment described in the EP5 document of the National Committee for Clinical Laboratory Standards (25), including two replicates per specimen per run and one run per day for 20 days. In addition, the analytical imprecision of total creatine kinase measurement with the present method was monitored daily with internal quality-control material consisting of pooled human serum. The monthly standard deviation over 4 months ranged from 4.7 to $6.5 \mathrm{U} / 1$ with a mean activity of nearly $100 \mathrm{U} / 1$; the mean standard deviation was $5.3 \mathrm{U} / 1$, giving a coefficient of variation of $5.3 \%$, which compared favourably with common routine assays for creatine kinase determination.

\section{Interference studies}

Components of uraemic plasma such as urea, creatinine, and uric acid do not interfere up to concentrations of 85 $\mathrm{mmol} / \mathrm{l}, 4500 \mu \mathrm{mol} / \mathrm{l}$, and $3000 \mu \mathrm{mol} / \mathrm{l}$, respectively. We also found no interference by bilirubin (up to 340 $\mu \mathrm{mol} / \mathrm{l}$ ), haemoglobin (up to $1 \mathrm{~g} / \mathrm{l}$ ), triacylglycerols (up to $12 \mathrm{mmol} / \mathrm{l}$ ), glucose (up to $55 \mathrm{mmol} / \mathrm{l}$ ), or adenylate kinase (up to $0.5 \mathrm{mg} / \mathrm{l}$ ).

\section{Method comparison}

The results of the analytical comparison between the immunoinhibition assay and the immunochemical assay for

Tab. 2 Analytical imprecision of creatine kinase isoform ratio determination by the evaluated method.

\begin{tabular}{|c|c|c|c|c|c|}
\hline \multirow{2}{*}{$\begin{array}{l}\text { Mean total } \\
\text { creatine } \\
\text { kinase } \\
(U / 1)\end{array}$} & \multirow{2}{*}{$\begin{array}{l}\text { Creatine } \\
\text { kinase } \\
\text { isoform } \\
\text { ratio* } \\
\bar{x}\end{array}$} & \multicolumn{2}{|c|}{$\begin{array}{l}\text { Within-run } \\
\text { imprecision }\end{array}$} & \multicolumn{2}{|c|}{$\begin{array}{l}\text { Total } \\
\text { imprecision }\end{array}$} \\
\hline & & SD & $\begin{array}{l}\text { CV } \\
(\%)\end{array}$ & $\mathrm{SD}$ & $\begin{array}{l}C V \\
(\%)\end{array}$ \\
\hline 61 & 0.51 & 0.072 & 14.13 & 0.108 & 21.16 \\
\hline 213 & 1.67 & 0.080 & 4.77 & 0.109 & 6.52 \\
\hline 340 & 2.50 & 0.118 & 4.72 & 0.149 & 5.93 \\
\hline
\end{tabular}

All runs were performed with a single lot number of reagent kits. *: creatine kinase isoform ratio was calculated as follows: total creatine kinase catalytic concentration - residual creatine kinase catalytic concentration/residual creatine kinase catalytic concentration: 


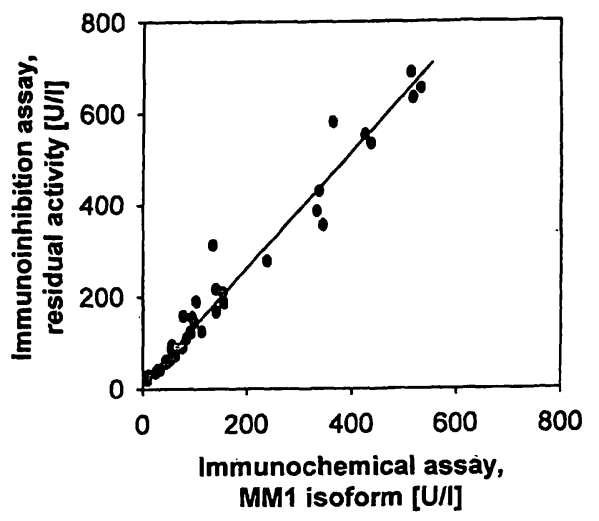

Fig. 1 Correlation of results for non-inhibited creatine kinase activity by immunoinhibition assay ( $y$-axis) with those for MM1 isoform by the immunochemical assay ( $x$-axis).

Linear regression analysis yields a regression equation of $y=1.24 x+14.2$ (solid line) with coefficient of correlation of 0.9815 and a standard error of estimate of 38.4 .

The number of patient samples was 39 and total creatine kinase activities of sera ranged from 23 to $4098 \mathrm{U} / \mathrm{l}$.

39 individual random samples submitted to our clinical laboratory are shown in figure 1 . As can be seen, the results showed a close overall correlation.

Correlation of the creatine kinase isoform ratios determined by the proposed method $(y)$ with those determined by Helena's electrophoretic method (x: MM3/ MM1 isoform ratio) yielded a regression equation of $y=0.56 x+0.92$, with a correlation coefficient of $0.9075(n=93)$. Values for total creatine kinase were also compared for patient sera assayed by both the present method (without CKM-G01 antibody) (y) and the method recommended by the International Federation of Clinical Chemistry (x). The correlation coefficient was 0.9992 and the regression equation was $y=1.03 x-1.7$ $(n=91)$. This good correlation allows the calculation of the isoform ratio independently of the enzyme assay used for total creatine kinase determination.

\section{Reference interval}

To establish the reference interval of the creatine kinase isoform ratio, sera were studied from 128 healthy subjects with total creatine kinase activity within the reference interval for our laboratory (upper reference limit, $160 \mathrm{U} / \mathrm{l}$ for women and $190 \mathrm{U} / 1$ for men). We then calculated the reference interval, using non-parametric determination of percentiles. Reference ranges of the isoform ratio, defined as 2.5 th -97.5 th percentile, were $0.14-$ 0.79 in females and $0.19-0.95$ in males (Wilcoxon ranksum test, $p=0.0046$ ), indicating a slight preponderance of the M(lysine)-monomer in men (fig. 2). An age difference was not detectable in the age range 20 to 70 years.

\section{Comparison studies in patients with} myocardial infarction

There is a more rapid and early increase in serum creatine kinase isoforms after successful coronary reperfusion in patients with acute myocardial infarction. We therefore compared the change in creatine kinase isoform activities and ratios determined with both immunoinhibition and electrophoretic assays over the first hours after therapy in patients with and without coronary recanaliżation, verified by independent criteria (figs. 3 and 4). Also in this particular clinical situation the results from the immunoinhibition assay correlated well with those from the conventional electrophoretic method. Figure 5 shows the time-course of the creatine kinase isoform ratio determined by the immunoinhibition assay, compared with total creatine kinase activity, myoglobin and creatine kinase $\mathrm{MB}$ concentrations in the same patients. As can be seen, the time-course of the isoform ratio after thrombolysis was similar to the sharp profile of myoglobin release into the circulation, particularly in the reperfused patients.

Since the most promising application of biochemical markers for the early detection of myocardial reperfusion involved examining the rate of increase of the marker in the blood, we compared the rate of increase of the creatine kinase isoform ratio with the rates of increase of total creatine kinase activity and of myoglobin and creatine kinase $\mathrm{MB}$ concentrations in the two groups of patients in the first two hours after thrombolytic therapy (tab. 3). The rates of release of total creatine kinase and creatine kinase MB in reperfused
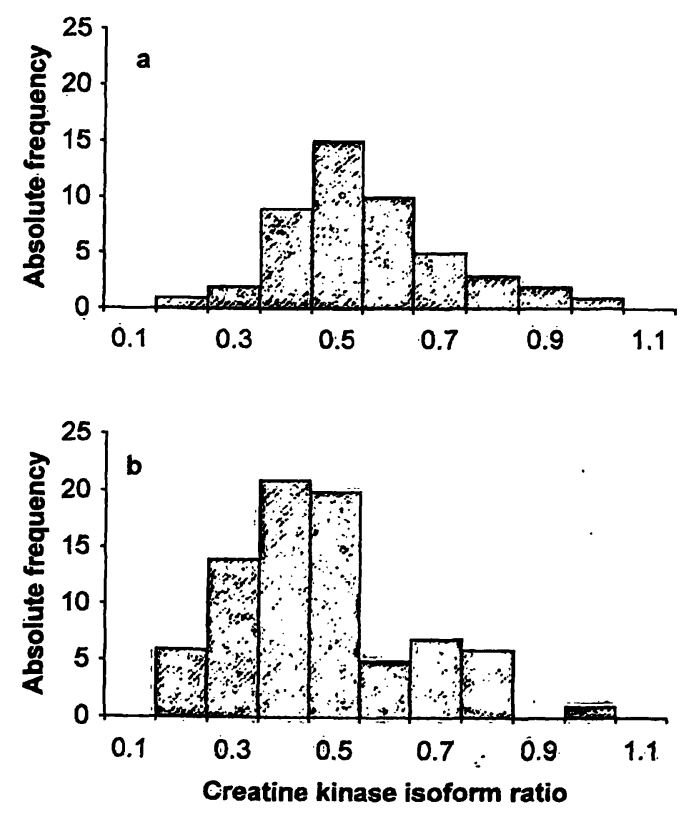

Fig. 2 Frequency histograms of the creatine kinase isoform ratio determined by the immunoinhibition method for the studied reference population;

(a) males; (b) females. 


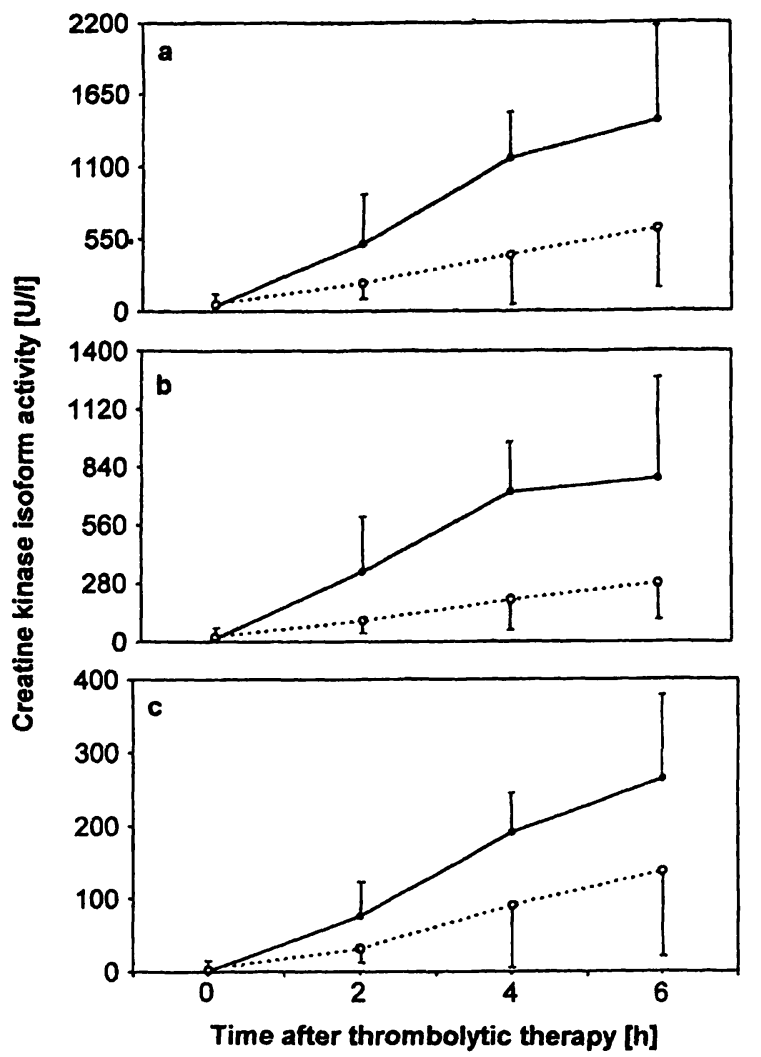

Fig. 3 Time-variable profiles of creatine kinase isoforms (mean values $\pm S D$ ) from myocardial infarction patients after thrombolytic therapy (solid line, reperfused; dashed line, not reperfused).

(a) Creatine kinase tissue isoforms (M(lysine)-monomer inhibited activity) by immunoinhibition assay;

(b) MM3 isoform and

(c) MB2 isoform activity by electrophoresis.

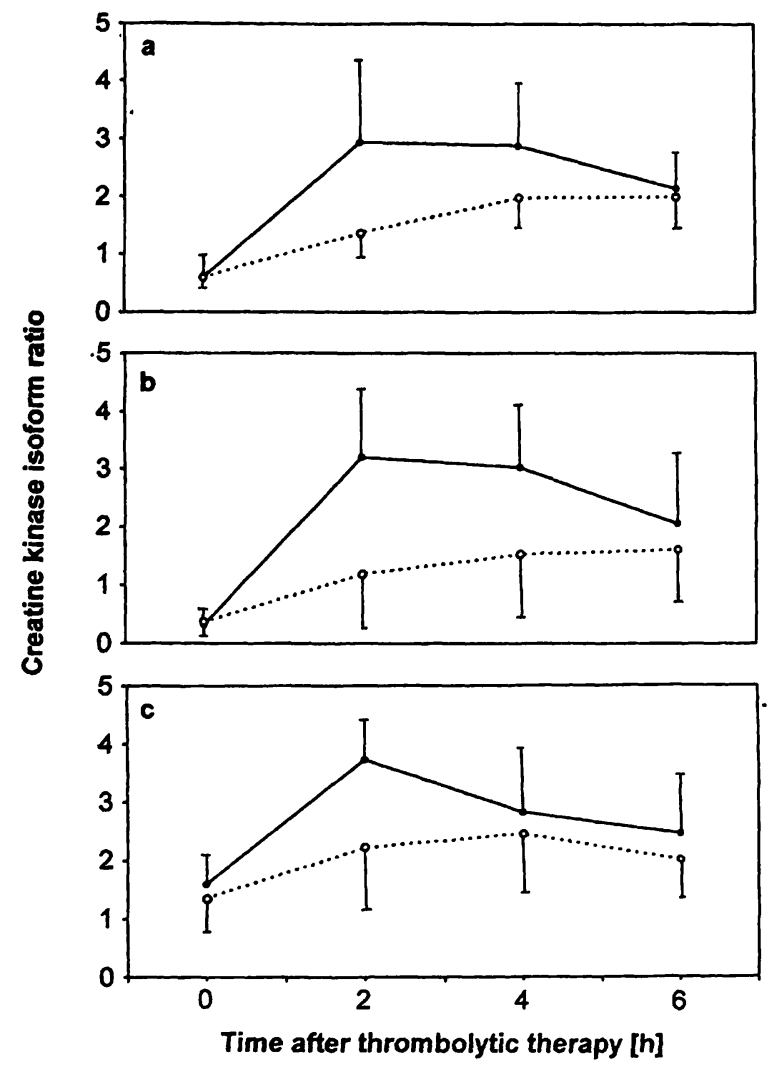

Fig. 4 Time-variable profiles of creatine kinase isoform ratios (mean values \pm SD) from myocardial infarction patients after thrombolytic therapy (solid line, reperfused; dashed line, not reperfused).

(a) Creatine kinase isoform ratio by immunoinhibition assay;

(b) $\mathrm{MM} 3 / \mathrm{MM} 1$ isoform ratio by electrophoresis and

(c) $\mathrm{MB} 2 / \mathrm{MB} 1$ isoform ratio by electrophoresis.

patients were significantly greater than in non-reperfused myocardial infarction patients. On the other hand, although their rates of release were higher in the reperfused group, the differences for myoglobin and the isoform ratio were not statistically significant, owing to the small number of patients studied.

\section{Discussion}

CKM-G01 was the first monoclonal antibody to be reported that inhibited the native $M$ subunit of creatine kinase, but not after removal of lysine from the subunit by carboxypeptidase (15). Recently, an automatable diagnostic test, based on the immunoinhibition method, and not requiring separation of isoforms, was developed with the use of this antibody $(16,17)$. Accordingly, the assay can reliably distinguish tissue $\mathrm{M}$ (lysine)-monomer from circulating monomer with no carboxy-terminal lysine, yielding a derived isoform ratio (inhibited/residual activity) which could be used for early diagnosis of myocardial infarction and coronary artery recanalization $(1,4)$. Current methods for measuring this ratio (tissue/ 
Tab. 3 Rate of increase (mean \pm SD) in the blood of myoglobin, total creatine kinase, creatine kinase MB, and creatine kinase isoform ratio in patients with acute myocardial infarction in the first two hours after thrombolytic therapy.

\begin{tabular}{lccc}
\hline & $\begin{array}{l}\text { Reperfused } \\
(\mathrm{n}=5)\end{array}$ & $\begin{array}{l}\text { Non-reperfused } \\
(\mathrm{n}=5)\end{array}$ & $\begin{array}{l}\text { Significance of } \\
\text { difference }(\mathrm{p})\end{array}$ \\
\hline Myoglobin, $\mu \mathrm{g} / \mathrm{l}$ min & $15.6 \pm 15.5$ & $3.5 \pm 2.4$ & 0.159 \\
Total creatine kinase, $\mathrm{U} / \mathrm{l}$ min & $6.6 \pm 3.5$ & $0.9 \pm 0.7$ & $i$ \\
Creatine kinase MB, $\mu \mathrm{g} / \mathrm{l}$ min & $1.0 \pm 0.5$ & $0.2 \pm 0.1$ & 0.024 \\
Creatine kinase isoforms, ratio per minute & $0.02 \pm 0.01$ & $0.006 \pm 0.004$ & 0.031 \\
\hline
\end{tabular}

serum isoforms) are generally time-consuming and complicated. At the present time, creatine kinase isoforms are not assayed routinely, mainly because of the difficulty in incorporating such a technique into the clinical laboratory routine, to be used on a 24-hours-per-day, 7 days-per-week basis, as demanded by clinicians (10). A rapid turnaround time for the assay is essential if additional interventions are to be implemented on the basis of the results. Consequently, a simple, reliable, and rapid analysis for measuring creatine kinase isoforms in serum is required. We presented evidence for the adequacy of the immunoinhibition assay, which is nearly as accurate as the electrophoretic procedure, a generally accepted analytical method whose assay performance is well documented $(1,6)$. The procedure can be fully mechanized on several types of automated analysers, permitting creatine kinase isoforms to be measured with a convenience approaching that of the total creatine kinase assay. There is one important shortcoming, namely the fact that the procedure cannot separate $M M$ and $M B$ isoforms. Compared with direct creatine kinase MB isoform measurement, this assay may be less specific for the early diagnosis of myocardial infarction (6). Thus, the test can be more useful for reperfusion studies than

\section{References}

1. Panteghini, M. (1988) Serum isoforms of creatine kinase isoenzymes. Clin. Biochem. 2I, 211-218.

2. Wu, A. H. B. (1989) Creatine kinase isoforms in ischemic heart disease. Clin. Chem. 35, 7-13.

3. Perryman, M. B., Knell, J. D. \& Roberts, R. (1984) Carboxypeptidase-catalyzed hydrolysis of C-terminal lysine: Mechanism for in vivo production of multiple forms of creatine kinase in plasma. Clin. Chem. 30, 662-664.

4. Apple, F. S. (1989) Diagnostic use of CK-MM and CK-MB isoforms for detecting myocardial infarction. Clin. Lab. Med. 9, 643-654.

5. Wu, A. H. B., Gornet, T. G., Wu, V. H., Brockie, R. E. \& Nishikawa, A. (1987) Early diagnosis of acute myocardial infarction by rapid analysis of creatine kinase isoenzyme- 3 subtypes. Clin. Chem. 33, 358-362.

6. Wu, A. H. B., Wang, X. M., Gornet, T. G. \& Ordonez-Llanos, J. (1992) Creatine kinase MB isoforms in patients with skeletal muscle injury: Ramifications for early detection of acute myocardial infarction. Clin. Chem. 38, 2396-2400. for early diagnosis, because the former are not limited by the problem of low clinical specificity (a working diagnosis of infarction has already been established). As recently confirmed by Adams et al. (26), criteria based on both the rate of rise and absolute values of creatine kinase isoforms in plasma may be capable of distinguishing patients with persistent recanalization from those with transient reperfusion followed by occlusion.

\section{Conclusion}

The use of the proposed assay offers a simple and reliable method for quantification of creatine kinase isoforms in serum. In particular, the results are obtained within 10 minutes and can be made available during nights, weekends, and holidays in a stat lab. Laboratories could easily provide clinicians with values for creatine kinase isoforms in emergency situations for prospective patient management.

\section{Acknowledgement}

We thank Mrs. O. Alebardi for technical assistance in the electrophoretic separation of creatine kinase isoforms. This study was partially supported by Poli Industria Chimica, Milano, Italy.

7. Panteghini, M. \& Pagani, F. (1987) Isoforms of creatine kinase isoenzymes in serum in acute myocardial infarction after intracoronary thrombolysis. Clin. Chem. 33, 2039-2042.

8. Schofer, J., Ress Grigolo, G., Voigt, K. D. \& Mathey, D. G. (1992) Early detection of coronary artery patency after thrombolysis by determination of the MM creatine kinase isoforms in patients with acute myocardial infarction. Am. Heart J. 123, 846-853.

9. Laperche, T., Steg, P. G., Benessiano, J., Dehoux, M., Juliard, J. M., Himbert, D. \& Gourgon, R. (1992) Patterns of myoglobin and $\mathrm{MM}$ creatine kinase isoforms release early after intravenous thrombolysis or direct percutaneous transluminal coronary angioplasty for acute myocardial infarction, and implications for the early noninvasive diagnosis of reperfusion. Am. J. Cardiol. 70, 1129-1134.

10. Apple, F. S. (1992) Acute myocardial infarction and coronary reperfusion. Serum cardiac markers for the 1990s. Am. J. Clin. Pathol. 97, 217-226.

11. Bhayana, V., Cohoe, S., Leung, F. Y., Jablonsky, G. \& Henderson, R. A. (1993) Diagnostici evaluation of creatine kinase-2 
mass and creatine kinase- 3 and -2 isoform ratios in carly diagnosis of acute myocardial infarction. Clin. Chem. 39, 488495.

12. Panteghini, M., Bonora, R., Pagani, F. \& Alebardi, O. (1990) An immunochemical procedure for determination of creatine kinase 3 , (serum-specific) isoform in human serum evaluated. Clin. Biochem. 23, 225-228.

13. Harker, C. C. \& Wu, A. H. B. (1990) Early diagnosis of acute myocardial infarction (MI) upon initial hospital admission using $\mathrm{CK}-\mathrm{MB}_{2}$ isoform analysis. Clin. Chem. 36, 1128.

14. Christenson, R. H. (1993) Specificity of an immunochemical reagent for quantifying the isoforms of creatine kinase-MB. J. Clin. Lab. Anal. 7, 220-224.

15. Suzuki, T., Shiraishi, T., Tomita, K., Totani, M. \& Murachi, T. (1990) Monoclonal antibody inhibiting creatine kinase $M_{3}$ but not isoform $\mathrm{MM}_{1}$. Clin. Chem. 36, 153-156.

16. Suzuki, T., Tomita, K., Tsubota, H., Okabe, H., Uji, Y., Sugiuchi, H., Takagi, Y., Gomi, K. \& Katayama, Y. (1990) Clinical significance of CK-MM isoform measurement by immunoinhibition. Clin. Chem. 36, 1127.

17. Uji, Y., Sugiuchi, H., Okabe, H., Suzuki, T., Shiraishi, T. \& Tsubota, H. (1992) Simultaneous automated determination of serum total CK and CK-MM isoform. Clin. Chem. 38, 976.

18. Kondo, H., Shiraishi, T., Kageyama, M., Nagata, K. \& Tomita, T. (1987) Bacterial glucokinase as an enzymic reagent of good stability for measurement of creatine kinase activity. J. Clin. Biochem. Nutr. 3, 17-25.

19. Panteghini, M., Bonora, R. \& Pagani, F. (1991) Chemiluminescence immunoassay of creatine kinase $\mathrm{MB}$ with a monoclonal antibody to the $\mathrm{MB}$ isoenzyme evaluated. Giorn. It. Chim. Clin. 16, 23-29.
20. Delanghe, J. R., Chapelle, J. P. \& Vanderschueren, S. C. (1990) Quantitative nephelometric assay for determining myoglobin evaluated. Clin. Chem. 36, 1675-1678.

21. Lewis, B. S., Lew, A. S. \& Ganz, W. (1988) Bedside recognition of coronary artery reperfusion during thrombolytic therapy. In: Acute Coronary Care in the Thrombolytic Era (Califf, R. M., Mark, D. B. \& Wagner, G. S., eds.) pp. 260-272, Year Book Medical Publishers, Inc., Chicago.

22. Garabedian, H. D., Gold, H. K., Yasuda, T., Johns, J. A., Finkelstein, D. M., Gaivin, R. J., Cobbaert, C., Leinbach, R. C. \& Collen, D. (1988) Detection of coronary artery reperfusion with creatinc kinase-MB determinations during thrombolytic therapy: Correlation with acute angiography. J. Am. Coll. Cardiol. 11, 729-734.

23. Ellis, A. K., Little, T., Zaki Masud, A. R., Liberman, H. A., Morris, D. C. \& Klocke, F. J. (1988) Early noninvasive detcction of successful reperfusion in patients with acute myocardial infarction. Circulation 78, 1352-1357.

24. Burnett, R. W. (1980) Quantitative evaluation of linearity. Clin. Chem. 26, 644-646.

25. National Committee for Clinical Laboratory Standards (1992) NCCLS Tentative Guideline EP5-T2. Evaluation of Precision Performance of Clinical Chemistry Devices, 2nd. ed., National Committee for Clinical Laboratory Standards, Villanova.

26. Adams, J. E., Abendschein, D. R. \& Jaffe, A. S. (1993) Biochemical markers of myocardial injury. Is $M B$ creatine kinase the choice for the 1990s? Circulation 88, 750-763.

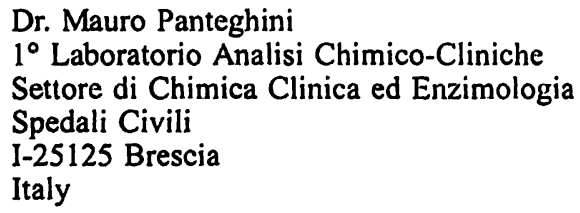


